\title{
Characteristic (Discriminant Function) Indices of Chironja, Orange and Grapefruit ${ }^{1}$
}

\author{
C. G. Moscoso and B. G. Capó
}

\section{INTRODUCTION}

Since the time chironja was discovered and described by Moscoso in $1956(2,3,4)$ scientists have shown interest in determining whether this citrus fruit may be considered genetically and somatically different from the orange and the grapefruit. A study of the morphological features of chironja, orange and grapefruit is reported herein.

Chironja is a new type of citrus fruit. It is juicy and sweet in flavor. It is high in vitamin $\mathbf{C}$ and low in acid content. It is a versatile fruit which may be utilized for juice, or cut in half and eaten with a spoon like a grapefruit. It peels easily and its sections can be eaten fresh like a tangerine, or it can be processed for canning.

\section{MATERIALS AND METHOD}

Samples of 100 fruits each of chironja, orange and grapefruit were taken from chironja seedling trees and from orange and grapefruit trees of undetermined varieties at the Corozal Substation. Several and diverse leaf, flower, fruit and juice characters of these three types of citrus fruits were measured, as follows:

Leaves: Length and width of blade and length of petiole and wing.

Flowers: Length and width of bud, petal, style, stamen, stigma and calyx, and length of peduncle and number of oil glands per petal.

Fruits: Length and diameter of fruit, sections and seeds, thickness of skin, number of seeds, weight of fruit and diameter of collar.

Juice: Brix, $\mathrm{pH}$, juice yield, solids, acid ratio and content of vitamin $\mathbf{C}$ and citric acid.

The mean, standard deviation and coefficient of variability were calculated for each of the characters measured of each type of fruit. ${ }^{8}$ Also, as described later, four discriminant functions were evaluated, each of which included only several leaf, flower, fruit or juice characters. These discriminant functions were developed by applying procedures developed by the junior author.

1 Manuscript submitted to Editorial Board March 1, 1972.

- Assistant Director and Technical Consultant, respectively, Agricultural Experiment Station, Mayagüez Campus, University of Puerto Rico, Río Piedras, P.R.

'The word "fruit" as used here refers either to the orange (Citrus sinensis), the grapefruit (C. paradisi) or the chironja. 
Fisher (1) suggested the use of a discriminant function to classify an individual into one of a number of alternative and mutually exclusive groups by taking measurements of several of its characters into consideration. In effect, the suggested procedure consists in estimating the parameters of an equation which would be used to calculate a characteristic index for any individual on the basis of characters, as well as the mean characteristic index for each such group. On the assumption that the characteristic indices are normally distributed, the probability of any individual belonging to one of the groups may then be calculated on the basis of its characteristic index. The parameters of the equation to be used for the evaluation of the characteristic indices are estimated so that the equation maximizes the differences between the mean characteristic indices of the groups, thus being useful to discriminate between the groups. This equation is known, therefore, as a discriminant function.

For the estimation of the parameters of a discriminant function, there are no "observed" characteristic indices of the individuals, the data consisting. solely of the measurements of their characters. This difficulty, however, is conveniently circumvented by using arbitrary but different initial values as "observed" characteristic indices for the various groups and fitting the discriminant function to the data by iteration. However, to reduce the number of approximations required for this fit, the following procedure may be conveniently used to estimate the initial characteristic index values:

1. Calculate both the group means and the general mean for each of the characters to be included in the functions. This is illustrated in the following tabulation in which it is assumed that two characters have been measured in each of nine individuals belonging to three different groups as follows: three to Group $N$, four to Group $T$, and two to Group $C$. The measurements of character $A$ are shown in the column headed by $X_{A}$ and the measurements of character $B$ are shown in the column headed by $X_{B}$. The groups means are 4, 5 and 3 for character $A$; and 7, 14 and 10 for character $B$. The general means of these characters are 4.2 and 10.8.

\begin{tabular}{lcc}
\multicolumn{3}{c}{ Totals and means of "species" } \\
\multicolumn{2}{c}{ Species } & Observations on charocters $A$ and $B$ \\
\cline { 2 - 3 }$N$ & $X_{A}$ & $X_{B}$ \\
$N_{1}$ & 3 & 8 \\
$N_{2}$ & 4 & 6 \\
$N_{8}$ & 5 & 7 \\
Total & - & - \\
Mean & 12 & 21 \\
& 4 & 7
\end{tabular}




\begin{tabular}{|c|c|c|}
\hline Species & Observations a & ors $A$ and $B$ \\
\hline$N$ & $x_{\Delta}$ & $X_{B}$ \\
\hline$T$ & & \\
\hline$T_{1}$ & 4 & 10 \\
\hline$T_{2}$ & 4 & 15 \\
\hline$T_{3}$ & 5 & 13 \\
\hline$T_{4}$ & 7 & 18 \\
\hline & - & - \\
\hline Total & 20 & 56 \\
\hline Mean & 5 & 14 \\
\hline$C$ & & \\
\hline$C_{1}$ & 4 & 7 \\
\hline$C_{2}$ & 2 & 13 \\
\hline t & - & - \\
\hline Total & 6 & 20 \\
\hline Mean & 3 & 10 \\
\hline Grand total & 38 & 97 \\
\hline & 4.2 & 10.8 \\
\hline
\end{tabular}

2. Calculate for each group the ratios of the mean values of the various characters to the corresponding general character means and calculate the mean of these ratios. In the following tabulation, the above-mentioned ratios for Group $N$ are $4 / 4.2$ and $7 / 10.8$, and the mean of these ratios, as indicated, is 0.80 . For Groups $T$ and $C$ the ratio means are 1.24 and 0.81 .

Ralios and ratio means

$$
\begin{array}{ll}
\text { Specics } & \\
N & \frac{4}{4.2}+\frac{7}{10.8}=1.60 ; \frac{1.60}{2}=0.80 \\
T & \frac{5}{4.2}+\frac{14}{10.8}=2.48 ; \frac{2.48}{2}=1.24 \\
\text { mean }
\end{array}
$$

3. Calculate the mean of the ratio means and the algebraic deviation of each group mean from this general mean. In the tabulation, the general mean is 0.95 , and the deviations from this mean of the group ratio means are $-0.15,0.29$ and -0.14 . These deviations are the values to be used tentatively as characteristic values for the 3 groups respectively. 
Tentative characteristic indices

Mean of ratio means:

$$
\frac{0.80+1.24+0.81}{3}=0.95
$$

Deviations of ratio means from the mean of the ratio means

$\begin{array}{ccr}\text { Species } & & \\ N & 0.80-0.95= & -0.15 \\ T & 1.24-0.95= & 0.29 \\ C & 0.81-0.95= & -0.14\end{array}$

The parameters of the discriminant function may now be estimated by iteration as follows:

1. Write the "observation" equations by using as "observed" value of the dependent variable of each individual the tentative characteristic index of its group. The discriminant function to be fitted to the data is linear:

$$
M+A X_{\Lambda}+B X_{B}=Y
$$

Because there are nine individuals, there are nine observation equations as follows:

$$
\begin{aligned}
& \text { Species Equations } \\
& \text { N } \quad M+3 A+8 B=-0.15 \\
& M+4 A+6 B=-0.15 \\
& M+5 A+7 B=-0.15 \\
& \text { T } \quad M+4 A+10 B=0.29 \\
& M+4 A+15 B=0.29 \\
& M+5 A+13 B=0.29 \\
& M+7 A+18 B=0.29 \\
& \text { C } \quad M+4 A+7 B=-0.14 \\
& M+2 A+13 B=-0.14
\end{aligned}
$$

Estimate the values of parameters $M, A$ and $B$ in these equations by the method of least squares. The estimates of the parameters in this first approximation are:

$$
M=-0.5078, A=0.0444, \text { and } B=0.0338
$$

The first approximation to the discriminant function is, therefore:

$$
Y=-0.5078+0.0444 X_{A}+0.0338 X_{B}
$$

2. Calculate the characteristic index for each individual by substituting in the first approximation to the discriminant function the observed values 
of its characters. The characteristic index for the first individual of species $N$ is thus:

$$
-0.5078+0.0444(3)+0.0338(8)=-0.1042
$$

The characteristic indices evaluated for all the individuals and the corresponding species means are as follows:

$\begin{array}{lr}\text { Indioiduals } & \begin{array}{c}\text { Claraderistic } \\ \text { indices }\end{array} \\ N_{1} & -0.1042 \\ N_{2} & -0.1274 \\ N_{3} & -0.0492 \\ & -0.2808 \\ \text { Total } & -0.0936 \\ \text { Mean } & -0.0936 \\ T_{1} & 0.0078 \\ T_{2} & 0.1768 \\ T_{3} & 0.1536 \\ T_{1} & 0.4114 \\ \text { Total } & -0.7496 \\ \text { Mean } & 0.1874 \\ C_{1} & -0.0936 \\ C_{2} & 0.0204 \\ \text { Total } & -0.0732 \\ \text { Mean } & -0.0366\end{array}$

3. Rewrite the observation equations by using for each individual of each group the species mean of the corrected characteristic indices of the individuals of its groups. The new observation equations for the three individuals of Group $N$ are thus:

$$
\begin{aligned}
& M+3 A+8 B=-0.0936 \\
& M+4 A+6 B=-0.0936 \\
& M+5 A+7 B=-0.0936
\end{aligned}
$$

The value of the dependent variable to be used in each of the four equations of the individuals of species $T$ is now 0.1874 , instead of 0.29 as used formerly, and for the two individuals of species $C,-0.0366$ instead of -0.14 .

Solve again these equations for $M, A$ and $B$, continue this process until there are no appreciable changes in the values of the characteristic indices of the three species. In this case, the final discriminant function is:

$$
Y=-0.2861+0.0204 X_{A}+0.0226 X_{B}
$$


The final characteristic indices of the nine individuals may be evaluated as indicated above by making use of the final discriminant function and an analysis of variance may be carried out of these final characteristic indices. The analysis of variance table is as follows:

$\begin{array}{lccc}\begin{array}{c}\text { Source of } \\ \text { varialion }\end{array} & \begin{array}{c}\text { Degrees of } \\ \text { freedom }\end{array} & \begin{array}{c}\text { Sum of } \\ \text { squares }\end{array} & \begin{array}{c}\text { Estimate o } \\ \text { variance }\end{array} \\ \text { Total } & 6 & 0.0944 & \\ \text { Species } & 2 & 0.0591 & 0.0295 \\ \text { Error } & 4 & 0.0353 & 0.0088\end{array}$

The total sum of squares has only 6 degrees of freedom since the evaluation of the characteristic indices of the nine individuals required the evaluation of three constants: $M, A$, and $B$. The error variance may be used to cal-

TABLE 1.-Characteristic indices which, on the basis of leaf characters, correspond to orange, chironja and grapefruit

$A$. Index equation

$$
Y=-3.2790-0.0008 X_{A}+0.0435 X_{B}+0.0531 X_{C}-0.0006 X_{D}
$$

$B$. Variables, mean values and indices

\begin{tabular}{|c|c|c|c|}
\hline \multirow{2}{*}{ Variables } & \multicolumn{3}{|c|}{ Means } \\
\hline & Orange & Chironja & Grapeiruit \\
\hline$A=$ Length of leaf & 105.96 & 141.91 & 118.88 \\
\hline B $=$ Width of leaf & 51.77 & 76.53 & 60.50 \\
\hline $\mathbf{C}=$ Length of petiole & 9.29 & 15.77 & 14.81 \\
\hline $\mathrm{D}=$ Length of wings & 96.59 & 126.14 & 104.26 \\
\hline Indices & -0.6772 & 0.6968 & -0.0196 \\
\hline \multicolumn{4}{|c|}{ C. Analysis of variance } \\
\hline Origin & DF & ss & Variance \\
\hline Total & 295 & 153.4265 & \\
\hline Types of citrus & 2 & 94.4593 & 47.2296 \\
\hline Error & 293 & 58.9672 & 0.2012 \\
\hline
\end{tabular}

D. Test of significance

\begin{tabular}{lcc}
\hline Comparison & $\begin{array}{c}\text { Standard error of the } \\
\text { difference }\end{array}$ & t value \\
\hline Orange-chironja & 0.0634 & $21.65^{* *}$ \\
Orange-grapefruit & .0634 & $10.36^{* *}$ \\
Chironja-grapefruit & .0634 & $11.29^{* *}$ \\
\hline
\end{tabular}

** Difference significant at the 1-percent probability level. 
culate the probability of any individual belonging to any of the 3 groups on the basis of the difference between its characteristic index, evaluated as indicated above, and the mean characteristic index of the group for which the probability referred to is to be calculated.

TABLE 2.-Characteristic indices which, on the basis of flower characters, correspond to orange, chironja and grapefruit

A. Index equation

$Y=-1.8689-0.0646 X_{A}+0.080 X_{B}+0.1691 X_{0}-0.0116 X_{D}$

B. Variables, mean values and indices

\begin{tabular}{lccc}
\hline \multirow{2}{*}{ Variables } & \multicolumn{3}{c}{ Means } \\
\cline { 2 - 4 } & Orange & Chironja & Grapefruit \\
\hline A = Length of bud & 16.44 & 17.99 & 14.17 \\
$\mathrm{~B}$ = Length of petal & 19.42 & 21.33 & 13.56 \\
$\mathrm{C}$ = Length of stamen & 13.46 & 16.97 & 9.83 \\
$\mathrm{D}=$ Number of oil glands per & 69.83 & 57.04 & 79.68 \\
\multicolumn{1}{c}{ petal } & & & \\
\multicolumn{1}{c}{ Indices } & 0.0847 & 0.8806 & -0.9653 \\
\hline
\end{tabular}

C. Analysis of variance

\begin{tabular}{lrrr}
\hline \multicolumn{1}{c}{ Origin } & DF & SS & Variance \\
\hline Total & 295 & 226.7748 & \\
Types of citrus & 2 & 171.4287 & 85.7143 \\
Error & 293 & 55.3461 & 0.1888 \\
\hline
\end{tabular}

D. Test of significance

\begin{tabular}{lcc}
\hline \multicolumn{1}{c}{ Comparison } & $\begin{array}{c}\text { Standard error of the } \\
\text { difference }\end{array}$ & i Value \\
\hline Orange-chironja & 0.0614 & $12.94^{* *}$ \\
Orange-grapefruit & .0614 & $17.08^{* *}$ \\
Chironja-grapefruit & .0614 & $30.03^{* *}$ \\
\hline
\end{tabular}

** Difference significant at the 1-percent probability level.

\section{RESULTS}

The procedure to fit the discriminant function as described above was applied to the group of characters of chironja, grapefruit, and orange previously mentioned. Measurements were taken of the leaves, flowers, fruits and juice characters. The discriminant functions fitted to the data and the corresponding mean characteristic indices of the three fruits and their corresponding statistical comparisons are presented in tables 1 to 4 . 


\section{LEAF CHARACTERS}

As shown in table 1, the characteristic indices of chironja, grapefruit and orange estimated from the length and width of the leaves and from the length of the petioles and wings are $0.6968,-0.0196$ and -0.6772 , which show highly significant differences between any pair of them. The

TABLD 3.-Characteristic indices which, on the basis of fruit characters, correspond to orange, chironja, and grapefruit

$$
\begin{gathered}
A . \text { Index equation } \\
Y=-4.5302+0.0435 X_{A}+0.0065 X_{B}+0.0255 X_{0}-0.0024 X_{D}
\end{gathered}
$$

$B$. Variables, mean values and indices

\begin{tabular}{cccc}
\hline Variables & \multicolumn{3}{c}{ Means } \\
\cline { 2 - 4 } & Orange & Chironja & Grapefruit \\
\hline $\mathrm{A}$ = Length of fruit & 66.76 & 107.32 & 90.66 \\
$\mathrm{~B}=$ Length of segment & 60.94 & 85.08 & 75.25 \\
$\mathrm{C}=$ Number of seeds & 4.50 & 17.35 & 5.41 \\
$\mathrm{D}=$ Diameter of collar & 10.29 & 16.63 & 3.41 \\
Indices & -1.1364 & 1.0993 & 0.0371 \\
\hline
\end{tabular}

C. Analysis of variance

\begin{tabular}{lrrr}
\hline \multicolumn{1}{c}{ Origin } & DF & \multicolumn{1}{c}{ SS } & Variance \\
\hline Total & 295 & 273.9252 & \\
Types of citrus & 2 & 250.1239 & 125.0619 \\
Error & 293 & 23.8013 & 0.0812 \\
\hline
\end{tabular}

D. Test of significance

\begin{tabular}{lcl}
\hline \multicolumn{1}{c}{ Comparison } & $\begin{array}{c}\text { Standard error of the } \\
\text { difference }\end{array}$ & ivalue \\
\hline Orange-chironja & 0.0403 & $55.46^{* *}$ \\
Orange-grapefruit & .0403 & $29.11^{* *}$ \\
Chironja-grapefruit & .0403 & $26.35^{* *}$ \\
\hline
\end{tabular}

** Difference significant at the 1-percent probability level.

leaf chracteristic indices may be used, therefore, to differentiate between these three fruits (table 1, fig. 1).

Figure 1 shows the frequency distribution of the individual characteristic indices for the three fruits indicating that those corresponding to chironja are the highest. This index differentiates more effectively between chironja and orange. 


\section{FLOWER CHARACTERS}

The characteristic indices of the three fruits based on flower characters are presented in table 2 . These characters are the length of the buds, petals, and stamens, and the number of oil glands per petal. The respective estimated indices for chironja, grapefruit and orange are $0.8806,-0.9653$ and

TABLE 4.-Characteristic indices which, on the basis of juice characters correspond to orange, chironja and grapefruit

\section{A. Index equation}

$$
Y=3.7474+0.0055 X_{A}-0.0135 X_{B}+0.0008 X_{C}-1.3711 X_{D}
$$

$B$. Variables, mean values and indices

\begin{tabular}{crrr}
\hline \multirow{2}{*}{ Variables } & \multicolumn{3}{c}{ Mcans } \\
\cline { 2 - 4 } & Orange & Chironja & Grapefruit \\
\hline $\mathrm{A}=$ Juice weight & 129.23 & 208.92 & 260.68 \\
$\mathrm{~B}=$ Percent of juice & 57.69 & 47.46 & 51.36 \\
$\mathrm{C}=$ Citric-acid content & $1,002.49$ & 520.72 & $1,307.26$ \\
$\mathrm{D}=\mathrm{pH}$ & 3.61 & 3.95 & 3.13 \\
\multirow{2}{*}{ Indices } & & & 1.2236
\end{tabular}

\begin{tabular}{|c|c|c|c|}
\hline \multicolumn{4}{|c|}{ C. Analysis of variance } \\
\hline Origin & DF & SS & Variance \\
\hline Total & 295 & 261.6631 & \\
\hline Types of citrus & 2 & 228.4202 & 114.2101 \\
\hline Error & 293 & 33.2429 & 0.1134 \\
\hline \multicolumn{4}{|c|}{ D. Test of significance } \\
\hline Comparison & & $\begin{array}{l}\text { Standard error of the } \\
\text { difference }\end{array}$ & i Value \\
\hline Orange-chironja & & 0.0476 & $5.85^{* *}$ \\
\hline Orange-grapefruit & & .0476 & $35.60 * *$ \\
\hline Chironja-grapefruit & & .0476 & $41.45^{* *}$ \\
\hline
\end{tabular}

** Difference significant at the 1-percent probability level.

0.0847 (table 2). Again, there are highly statistical differences between any two pairs of these mean flower characteristic indices, indicating that they can also be used to differentiate between the three fruits (table 2, fig. 2). The frequency distribution of the individual flower characteristic indices are presented in figure 2, showing again that those of chironja are the highest. This index is particularly useful to differentiate between chironja and grapefruit. 


\section{FRUIT CHARACTERS}

Table 3 presents the mean characteristic indices of chironja, grapefruit and orange based on fruit characters. The fruit characters used were length of fruit, length of segment, number of seeds and diameter of collar. The frequency distributions of the individual fruit characteristic indices are presented in figure 3 (table 3, fig. 3).

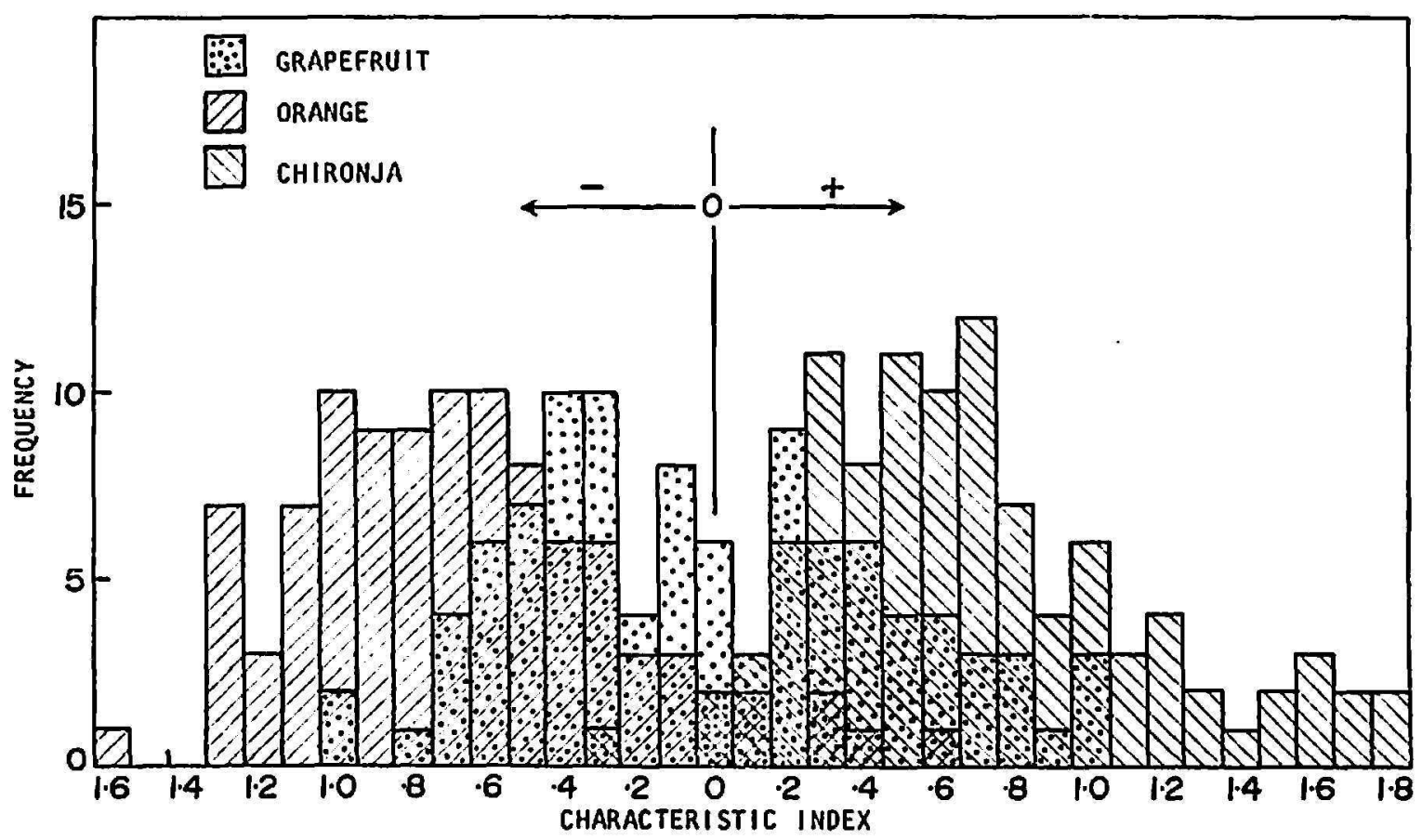

FIG. 1.-Frequency distribution of the characteristic indices of the leaves.

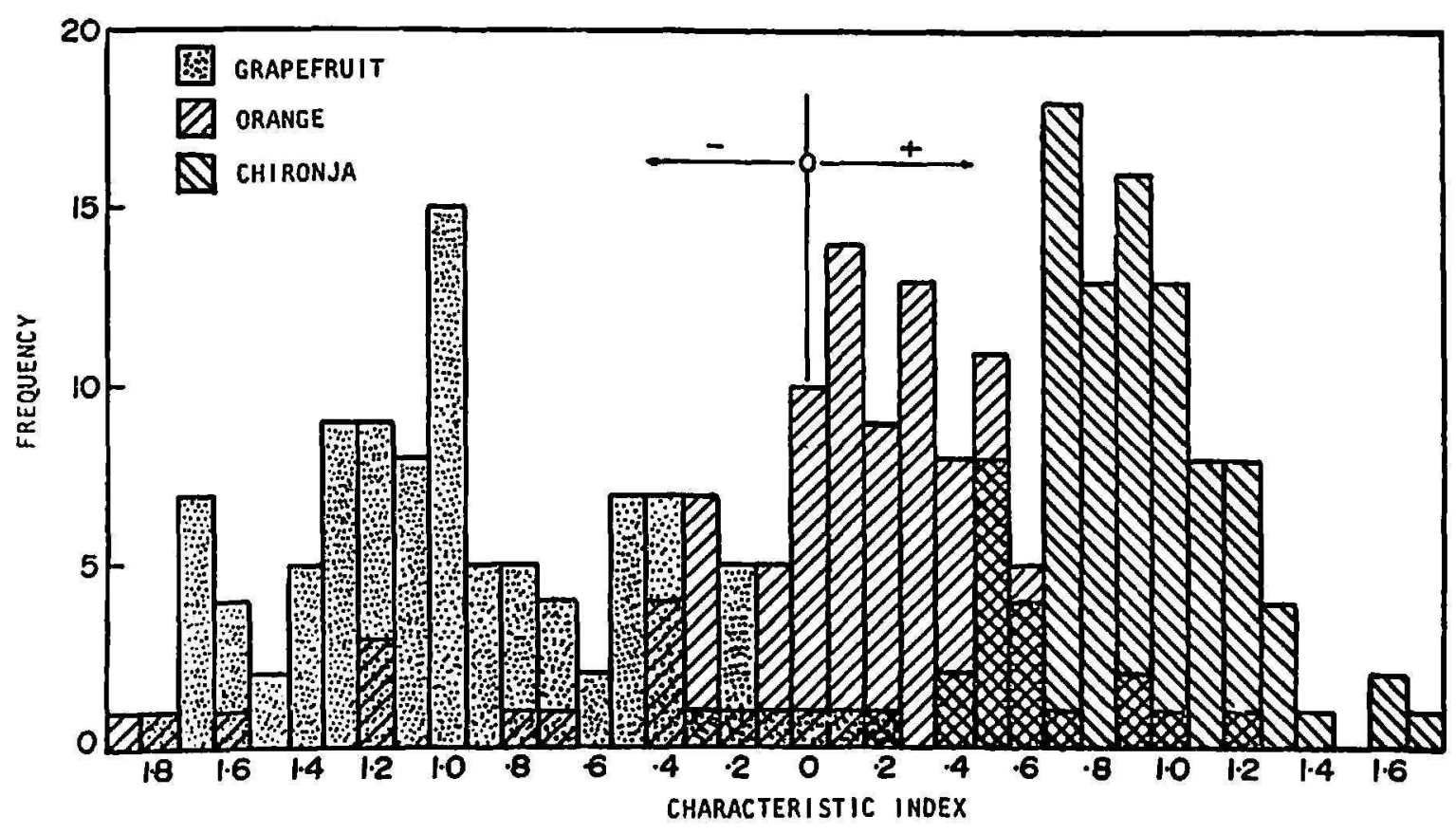

FIG. 2.-Frequency distribution of the characteristic indices of the flowers. 
The characteristic indices based on the above-mentioned fruit characters were greatest for chironja, and greater for grapefruit than for orange. As may be seen in figure 3 , this index discriminates with high precision between the three fruits.

\section{JUICE CHARACTERS}

Table 4 presents the characteristic indices based on juice characters for the three fruits species. The juice characters used to calculate the indices were weight of juice per fruit, percentage content by weight of juice in

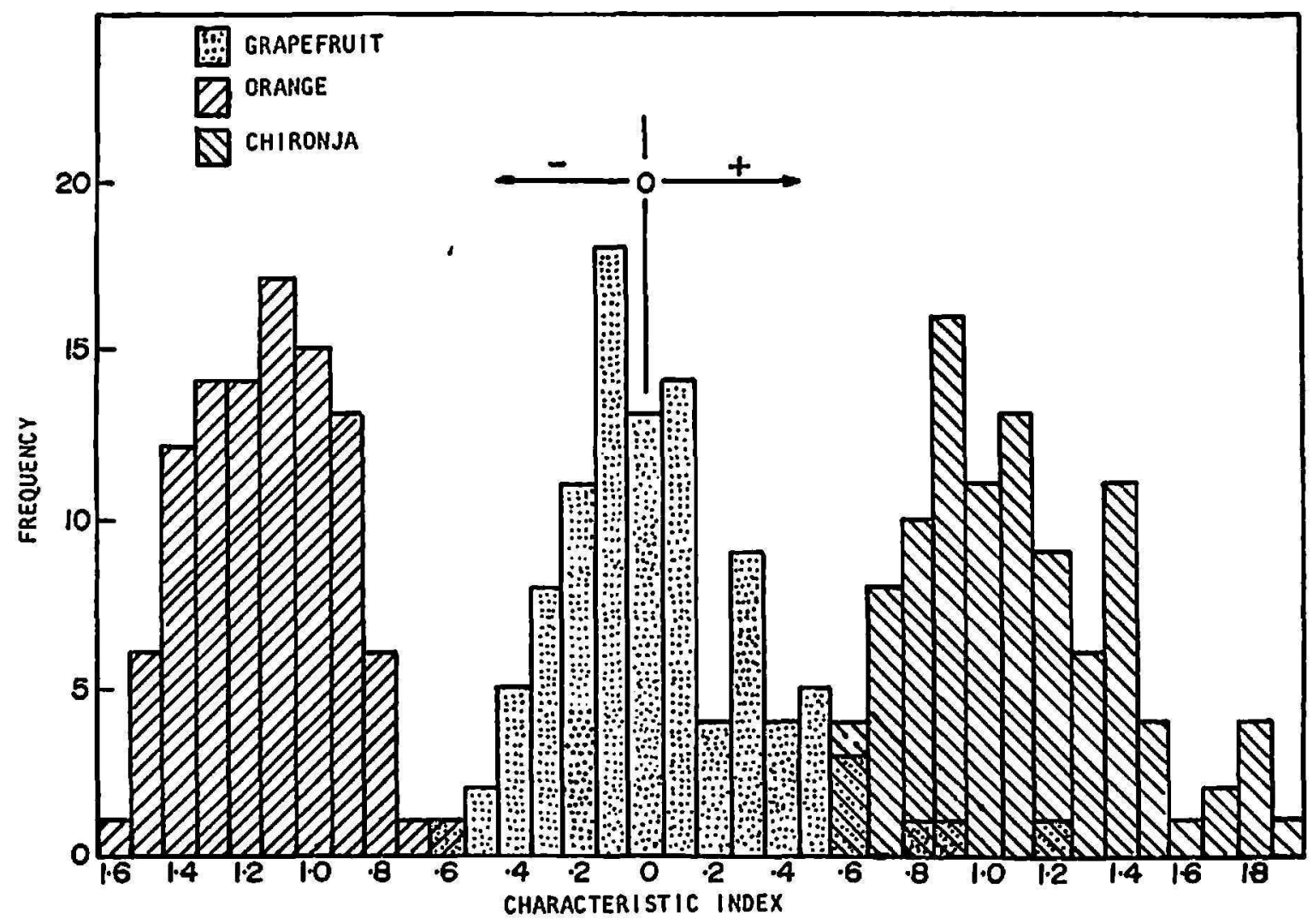

Fra. 3.-Frequency distribution of the characteristic indices of the fruits.

fruit, content of citric acid per 100 mls. of juice and $\mathrm{pH}$ of juice (table 4 , fig. 4).

This index can also be used to discriminate between the three fruits, especially to differentiate between grapefruit and either chironja or orange. Figure 4 presents the individual characteristic indices for grapefruit, orange and chironja juice.

\section{DISCUSSION}

The characteristic indices estimated from the four groups of characters discriminated at the 1-percent level of statistical significance between the 100 -fruit samples of each of these fruits. For the identification of a single 
fruit, however, the most useful index seems to be the one based on the fruit characters, as seen in figure 3 . In those instances in which the value of this index may be relatively low (from -0.8 to -0.4 ) or relatively high (from 0.2 to 0.4 ), the addition of the index based on juice characters would permit an almost fool-proof identification of the fruit in question.

\section{SUMMARY}

Statistical comparisons of samples of chironja, orange and grapefruit were made of the characters of the leaves, flowers, fruits, and juice. The

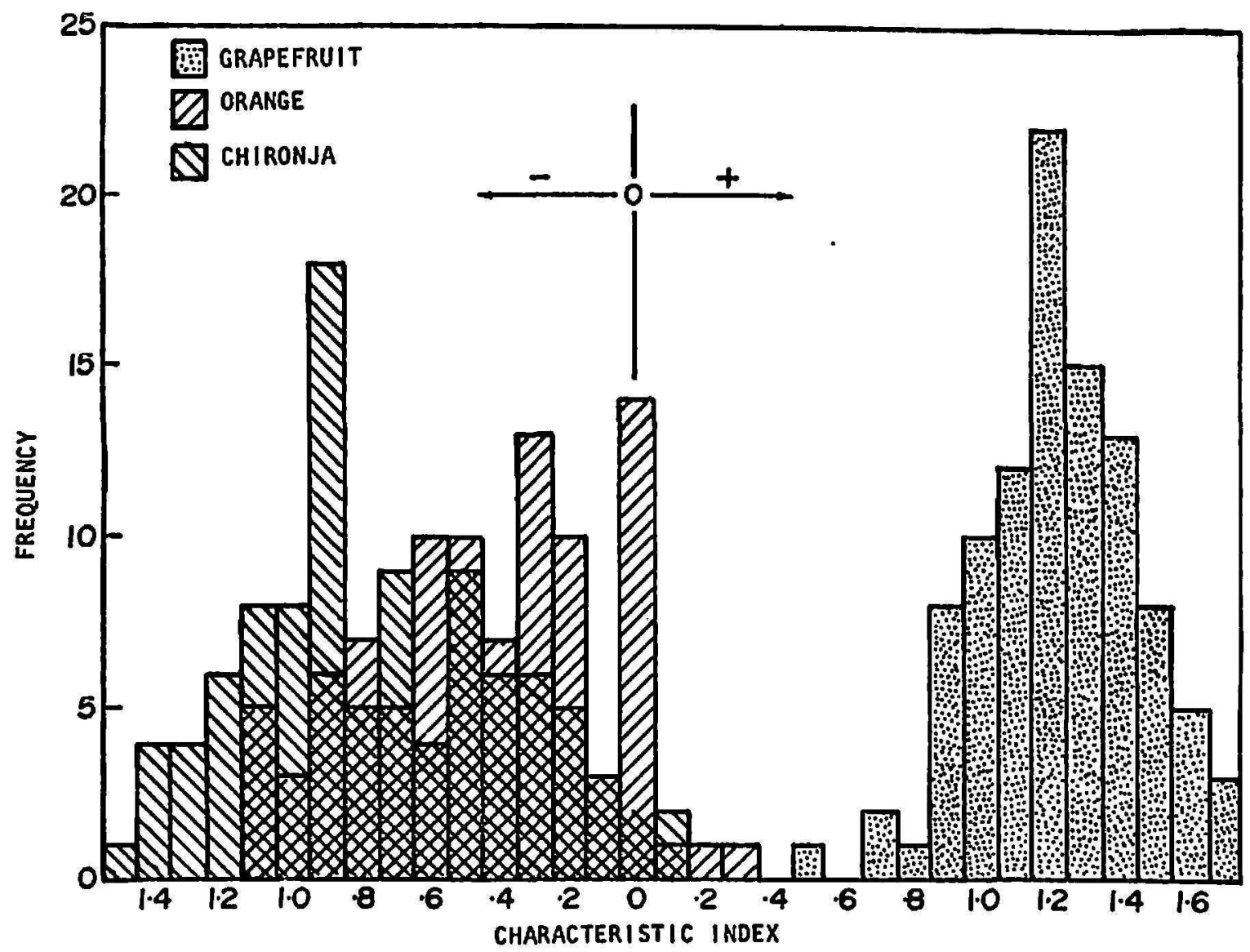

FIG. 4.-Frequency distribution of the characteristic indices of the juices.

comparisons demonstrated that these fruits differ with regard to the above-mentioned characters when the latter are combined to provide certain quality indices.

The four types of indices discriminated at the 1-percent level of statistical significance when comparing 100-fruit samples of each of the three fruits with each other.

It is suggested that in identifying a single fruit in accordance with the described procedure, the characteristic index based on fruit characters be used first. However, if the result of this test is not conclusive, the addi- 
tion of the characteristic index based on juice characters will aid in the identification of a single fruit with a high degree of accuracy.

\section{RESUMEN}

Se hicieron comparaciones estadísticas de los caracteres de las hojas, flores, frutas y jugos en muestras de chironja, naranja (china) y toronja. Estas comparaciones demostraron que los caracteres de las frutas arriba mencionados discriminan entre sí cuando se combinan para estimar ciertos indices característicos.

Todos los tipos de índices discriminaron significativamente al nivel estadístico del 1 por ciento en muestras de 100 frutas de cada una de las tres clases.

Se sugiere que para identificar una sola fruta mediante el procedimiento ya descrito, se use primero el índice característico basado en los caracteres de la fruta. No obstante, cuando los resultados de tal comparación no son conclusivos, la adición del índice basado en los caracteres del jugo ayudará a la identificación de una sola fruta con un alto grado de precisión.

\section{LITERATURE CITED}

1. Fisher, R. A., The Use of Multiple Measurements in Taxonomic Problems, Ann. Eugen. 7: 179-88, 1936.

2. Moscoso, C. G., The Puerto Rican Chironja-New All-Purpose Citrus Fruit, Econ. Bot., 12: 87-94, 1958.

3. Moscoso, C. G., The Puerto Rican Chironja-A New Type of Citrus, Trop. Prod. Inst., Proc., pp. 193-5, London, England, 1969.

4. Moscoso, C. G., Nueva Fruta que Posee Características Intermedias Entre la China y la Toronja, Revista del Café, September 1964. 